\title{
Penerapan Green Manufacturing pada IKM Dadi Mulyo
}

\author{
Irwan Sukendar, Eli Mas'idah, Raka Wisnu Prayuda \\ Universitas Islam Sultan Agung Semarang \\ Jurusan Teknik Industri, Universitas Islam Sultan Agung Semarang, Indonesia \\ email: irwan@unissula.ac.id, rakawisnuprayuda@std.unissula.ac.id
}

\begin{abstract}
IKM Dadi Mulyo produces wood sawdust waste of approximately $400 \mathrm{~kg} / \mathrm{day}$ which if left for days on end will accumulate more and pollute the company's environment and the surrounding environment. Green Manufacturing method is used to perform analysis to reduce waste and increase added value. The research was conducted by direct observation and interviews. The results of the analysis show that the application of green manufacturing is able to reduce waste and increase added value by $50 \%$. So that the increase in added value has the potential to improve the welfare of employees.
\end{abstract}

Keywords: Waste, Green manufacturing, Value stream mapping, Future Stream Mapping, Value Added

\begin{abstract}
Abstrak
IKM Dadi Mulyo menghasilkan limbah serbuk gergaji kayu kurang lebih 400 kg/hari yang apabila dibiarkan berhari-hari akan menjadi semakin menumpuk, mencemari lingkungan perusahaan dan lingkungan sekitar. Metode Green Manufacturing digunakan untuk melakukan analisis guna mengurangi pemborosan dan meningkatkan nilai tambah. Penelitian dilakukan dengan observasi langsung dan wawancara. Hasil analisis menunjukkan bahwa penerapan Green Manufacturing mampu mengurangi pemborosan dan meningkatkan nilai tambah sebesar $50 \%$. Sehingga peningkatan nilai tambah berpotensi untuk meningkatkan kesejahteraan karyawan.
\end{abstract}

Kata kunci: Waste, Green manufacturing, Value stream mapping, Future Stream Mapping, Value Added

\section{Pendahuluan}

IKM Dadi Mulyo merupakan IKM pengolahan kayu yang memproduksi berbagai jenis olahan kayu seperti papan, usuk, glugu, balok dan lain-lain. Produk yang dihasilkan kebanyakan dikirim ke proyek-proyek perumahan. Tingginya tingkat persaingan bisnis dalam industri kayu membuat IKM Dadi Mulyo harus meningkatkan kinerjanya, dan mengoptimalkan segala sumber daya yang dimilikinya. Di dalam industri pengolahan kayu mestinya tidak jauh dengan adanya limbah kayu yang dihasilkan. Di IKM Dadi mulyo terdapat banyak limbah yang dihasilkan berupa sebetan, potongan kayu, produk yang cacat dan serbuk gergaji kayu. Dari hal tersebut perusahaan harus memanfaatkan limbah yang dihasilkan sebaik mungkin sehingga limbah yang dihasilkan memiliki nilai ekonomis yang lebih.

Sehubungan dengan hal tersebut, IKM Dadi Mulyo memiliki permasalahan penumpukan limbah yang sangat banyak khususnya limbah serbuk gergaji kayu yang menumpuk. Pada IKM tersebut terdapat limbah serbuk gergaji kayu sebanyak kurang lebih $400 \mathrm{~kg} / \mathrm{hari}$ apabila didiamkan selama berhari hari tentunya akan menumpuk menjadi lebih banyak dan mencemari lingkungan perusahaan dan lingkungan sekitar. Di perusahaan tersebut belum ada penanganan limbah secara efektif disana limbah masih dijual begitu saja dan penjualan limbah serbuk gergaji kayu disana masih tergolong susah butuh waktu 15 hari 1 bulan untuk bisa 
menjual limbah tersebut karena pembeli limbah tersebut biasanya membeli limbah 1 bulan sekali.

Literatur riview yang digunakan pada penelitian ini adalah pemanfaatan limbah serbuk kayu di kota Denpasar, disini penelitian dilakukan pada limbah serbuk gergaji kayu yang dijadikan sebagai bricket [1], selanjutnya dari artikel analisis manfaat ekonomi limbah serbuk kayu yang ber isi tentang manfaat nilai ekonomi limbah serbuk gergaji kayu yang diolah terlebih dahulu [2], selanjutnya di jurnal pengolahan limbah serbuk kayu menjadi batu bata akustik membahas tentang bagaimana cara mengolah atau memanfaatkan limbah serbuk kayu menjadi batu bata akustik yang memiliki nilai jual tambah [3], dan jurnal implementasi lean manufacturing yang membahas tentang bagaimana penerapan lean manufacturing dalam suatu perusahaan [4].

Selain itu, jurnal tentang simulasi manufacturing tentang bagaimana cara melakukan manufacturing [5] jurnal tentang sustainable manufacturing [7] jurnal tentang manufacturing industri 4.0 [8] jurnal tentang material mechanic yang mebahas tentang bahan material mesin [9] jurnal tentang green manufacturing yang membahas tentang bagaimana green manufacturing teraplikasikan [10] jurnal tentang model sistem green manufacturing yang membahas tentang sistem green manufacturing [11] jurnal tentang limbah yang membahas tentang pengolahan limbah [12] jurnal tentang pemanfaatan limbah sebagai bahan dasar kacamata [13] dan jurnal tentang pemanfaatan limbah sebagai bahan dasar batu bara atau arang bricket [14]. Penelitian-penelitian tersebut telah sukses dalam mengurangi limbah untuk menuju Green Manufacturing.

\section{Metode Penelitian}

Metode penelitian ialah langkah-langkah penelitian saat melakukan sebuah penelitian atau pencarian solusi untuk mencari jalan keluar dari sehingga dapat berjalan dengan terstruktur, sistematis dan mempermudah dalam pengambilan kesimpulan dari hasil penelitian. Metode pada penelitian ini dimulai dari pengumpulan data. Adapun data-data yang dibutuhkan peneliti antara lain: data primer dan data sekunder.

Data primer merupakan data yang diperoleh langsung dari IKM atau data yang terjadi di lapangan yang diperoleh dari teknik wawancara khususnya dengan pihak yang berwenang dengan penelitian ini. Adapun data sekunder merupakan data yang diperoleh dari IKM dalam bentuk yang sudah jadi. Data yang diperoleh berupa data kualitatif dan kuantitatif

Teknik pengumpulan data yang digunakan dalam penelitian ini adalah berupa: observasi lapangan, yaitu pengumpulan data melalui pengamatan secara langsung, wawancara, yaitu pengumpulan data yang diperoleh melalui wawancara dengan pemilik usaha, serta studi pustaka, yang dilakukan melalui referensi dari beberapa sumber berupa buku-buku, jurnal, artikel ilmiah, dan lain-lain. Selanjutnya, data-data yang terkumpul dianalisis, dilakukan pembahasan dan disimpulkan.

\section{Hasil dan Analisis}

\section{1. pengumpulan Data}

Bagian ini berisi hasil, diskusi, analisis, dan pembahasan serta temuan-temuan yang dicapai. Pada tahap ini dilakukan pengumpulan data yang dibutuhkan dalam penelitian ini.

Tabel 1 Data Penumpukan Limbah di UD. Dadi Mulyo

\begin{tabular}{|c|c|c|c|}
\hline Jenis Limbah & Banyak per hari & Lama penumpukan & Total \\
\hline Serbuk kayu & $400 \mathrm{Kg}$ & 15 hari & $6.000 \mathrm{~kg}$ \\
\hline
\end{tabular}

Penumpukan limbah serbuk gergaji kayu di UD. Dadi Mulyo setiap harinya sebanyak 400 $\mathrm{kg}$, lama penumpukan limbah di perusahaan tersebut selama 15 hari. Jadi total penumpukan limbah serbuk gergaji kayu di UD. Dadi Mulyo setiap 15 hari-nya sebesar $6.000 \mathrm{~kg}$. Di perusahaan tersebut biasanya menjual limbah serbuk kayu setiap 15 hari sekali dengan estimasi penjualan sebagai berikut:

Tabel 2 Harga Serbuk Kayu di UD.Dadi Mulyo

\begin{tabular}{|c|c|c|}
\hline Banyak limbah dihasilkan & Harga per Kg & Total \\
\hline $6.000 \mathrm{Kg}$ & Rp. 200 & Rp. 1.200 .000 \\
\hline
\end{tabular}


Harga serbuk gergaji kayu di perusahaan tersebut sebesar Rp. 200,- per kilogram nya. Jadi apabila perusahaan menjual limbah serbuk kayu tanpa diolah terlebih dahulu maka pendapatan maksimal yang didapatkan setiap 15 hari atau penjualan limbahnya sebesar Rp. 1.200.000,-.

\subsection{Analisis Value Stream Mapping}

Metode yang digunakan untuk pengolahan data adalah metode Green Manufacturing dan metode sustainable manufacturing dengan membuat Value Stream Mapping terlebih dahulu guna melihat aliran material dari proses produksi penggergajian kayu. Pembuatan Value Stream Mapping untuk mengetahui aliran material.

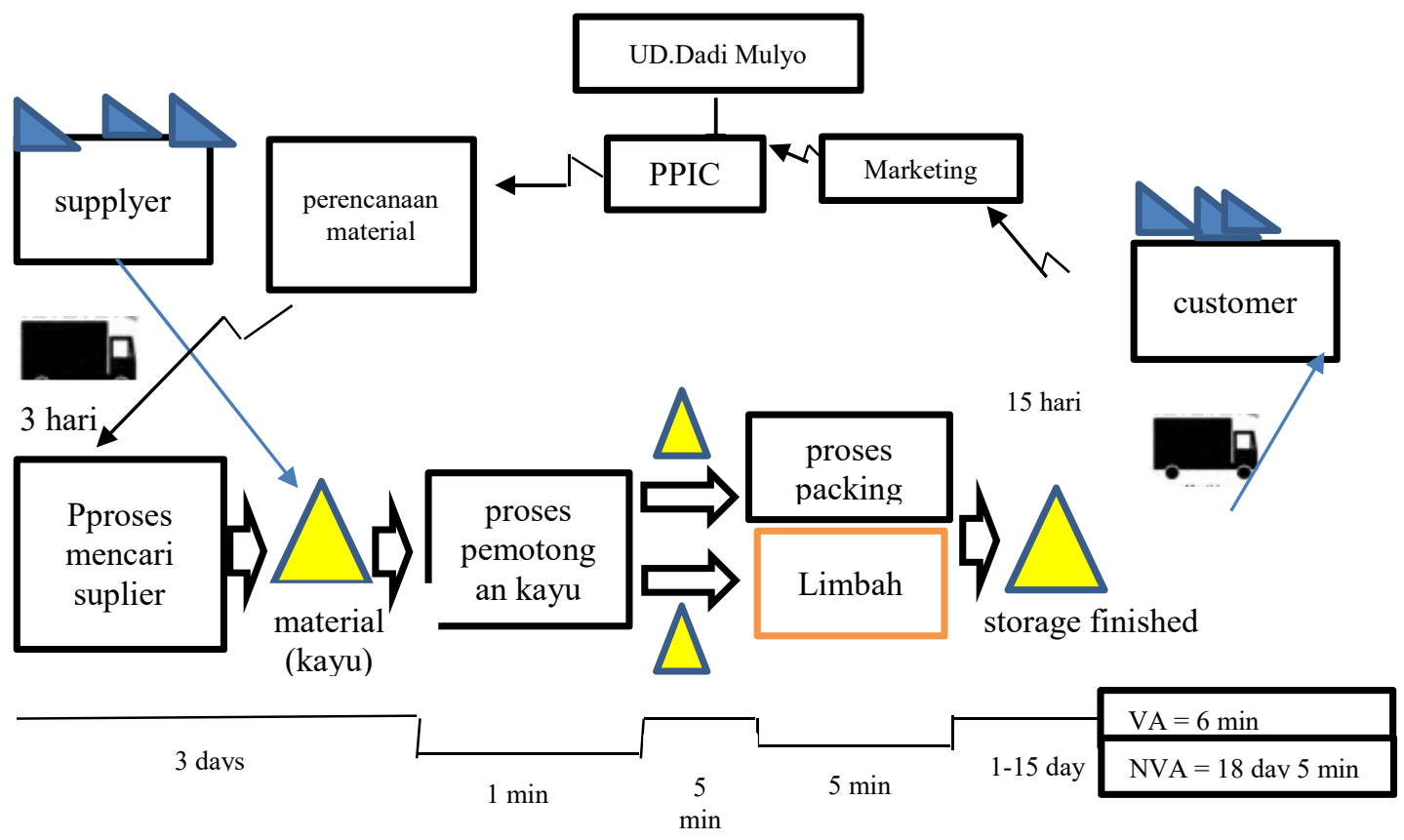

Gambar 1 Value Stream Mapping

Limbah yang dihasilkan melalui proses produksinya perharinya sebanyak $400 \mathrm{~kg}$ namun penjualan dari limbah tersebut terjual setelah sekitar 15-20 hari baru ada pembeli yang membeli limbah tersebut. Sehingga penumpukan limbah serbuk gergaji kayu selama 15 hari menjadi sebesar $6000 \mathrm{~kg}$ atau sebesar 6 ton.

Tabel 3 Perhitungan Value Stream Mapping

\begin{tabular}{|c|l|c|c|c|c|c|c|}
\hline \multirow{2}{*}{ No } & \multicolumn{2}{|c|}{ Ativitas } & Waktu & \multicolumn{3}{|c|}{ Aktivitas } & \multirow{2}{*}{ VA/NVA } \\
\cline { 3 - 6 } & & (hari/Jam) & O & T & S & D & \\
\hline 1 & Membeli Bahan Baku & 3 hari & & $\sqrt{ }$ & & & VA \\
\hline 2 & Penyimpanan Bahan Baku & 3 hari & & & $\sqrt{ }$ & & NNVA \\
\hline 3 & Pemotongan kayu & 1 menit & $\sqrt{ }$ & & & & VA \\
\hline 4 & Proses packing & 5 menit & $\sqrt{ }$ & & & & VA \\
\hline 5 & Timbul limbah & 5 menit & & & & $\sqrt{ }$ & NNVA \\
\hline 10 & Penyimpanan Finish Good & 15 hari & & & $\sqrt{ }$ & & NNVA \\
\hline
\end{tabular}

Keterangan: $O=$ Operation, $T=$ Transportation, $S=$ Storage, $D=$ Delay 


\subsection{Analisis Future Stream Mapping}

Pembuatan future stream mapping bertujuan untuk memperbaiki permasalahan timbulnya waste pada proses produksi kayu tersebut. Permasalahannya berfokus pada susahnya untuk menjual limbah serbuk gergaji kayu tersebut dalam jangka waktu 15 hari, sehingga limbah yang dihasilkan akan menumpuk selama 15 hari menjadi lebih banyak dan mengganggu lingkungan sekitar.

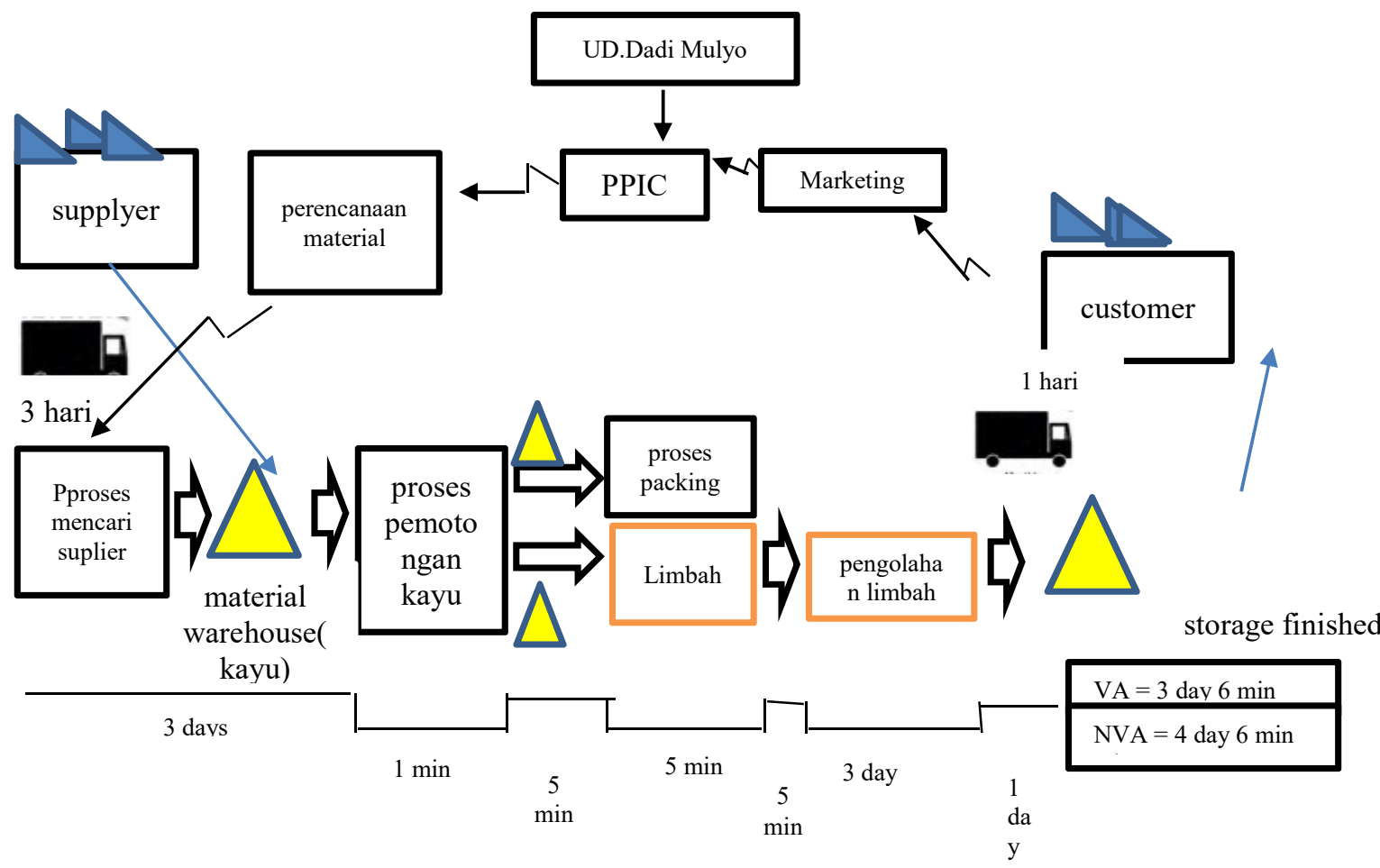

Gambar 2 Future Stream Mapping

Dari future stream mapping di atas diketahui bahwa perbaikan dilakukan pada penanganan limbah, penanganan limbah yang sebelumnya langsung dijual begitu saja dan membutuhkan waktu sekitar 15 hari, disini dilakukan perbaikan untuk mengolah limbahnya terlebih dahulu selama 3 hari dan setelah itu baru dijual.

Tabel 4 Perhitungan Value Stream Mapping

\begin{tabular}{|c|l|c|c|c|c|c|c|}
\hline \multirow{2}{*}{ No } & \multirow{2}{*}{ Ativitas } & Waktu & \multicolumn{3}{|c|}{ Aktivitas } & \multirow{2}{*}{ VA/NVA } \\
\cline { 3 - 6 } & & (hari/Jam) & O & T & S & D & \\
\hline 1 & Membeli Bahan Baku & 3 hari & & $\sqrt{ }$ & & & VA \\
\hline 2 & Penyimpanan Bahan Baku & 3 hari & & & $\sqrt{ }$ & & NNVA \\
\hline 3 & Pemotongan kayu & 1 menit & $\sqrt{ }$ & & & & VA \\
\hline 4 & Proses packing & 5 menit & $\sqrt{ }$ & & & & VA \\
\hline 5 & Timbul limbah & 5 menit & & & & $\sqrt{ }$ & NVA \\
\hline 6 & Pengolahan limbah & 3 hari & $\sqrt{ }$ & & & & VA \\
\hline 10 & Penyimpanan Finish Good & 1 hari & & & $\sqrt{ }$ & & NNVA \\
\hline
\end{tabular}

Keterangan: $O=$ Operation, $T=$ Transportation, $S=$ Storage, $D=$ Delay 


\subsection{Perbandingan dan Pembahasan}

Hasil akhir penelitian dibandingkan pada Tabel 5 di bawah ini.

Tabel 5 Perbandingan VSM dan FSM

\begin{tabular}{|l|l|l|}
\hline & Value Stream Mapping Awal & Future Stream Mapping \\
\hline VA & 6 min & 9 menit \\
\hline NVA & 15 hari 5 menit & 5 menit \\
\hline NNVA & 7 hari & 7 hari \\
\hline
\end{tabular}

Berdasarkan Perbandingan nilai VSM dan FSM, tampak bahwa FSM memiliki peningkatan nilai yang VA yaitu dari 6 menit menjadi 9 menit atau mengalami peningkatan sebesar $50 \%$. Sementara nilai NVA mengalami penurunan sangat signifikan dari 15 hari 5 menit menjadi 5 menit. Dan nilai NNVA tetap sebesar 7 hari.

\section{Kesimpulan}

Berdasarkan hasil penelitian, maka dapat ditarik kesimpulan yaitu: penerapan metoda Green Manufacturing pada IKM Dadi Mulyo mampu meningkatkan nilai tambah (value added) sebesar $50 \%$. Dengan peningkatan nilai tambah ini, bisa digunakan untuk menambah kesejahteraan para karyawan IKM.

\section{Referensi}

[1] I. W. Sutarman, "Pemanfaatan Limbah Industri Pengolahan Kayu Di Kota Denpasar (Studi Kasus Pada Cv Aditya)," J. PASTI, vol. 10, no. 1, pp. 15-22, 2016.

[2] Bahri S., "Pemanfaatan Limbah Industri Pengolahan kayu untuk pembuatan briket arang dalam mengurangi pencemaran lingkungan di Nangroe Aceh Darussalam," J. Mek., vol. vol.4 no.2, pp. 410-415, 2007.

[3] I. N. Tika, I. G. Ayu, T. Agustiana, D. Agus, and W. Erawan, "Pengolahan Limbah Serbuk Gergaji Kayu Menjadi Bata Akustik," pp. 585-593, 2017.

[4] I. Artikel, "Jurnal SENOPATI," pp. 50-61, 2019.

[5] U. Malik, "Jurusan Fisika Fakultas Matematika dan Imu Pengetahuan Alam Universitas Riau,” vol. I, no. 2, pp. 21-26, 1994.

[6] P. O. Box and S. Lind, "Proceedings of the 2008 Winter Simulation Conference S. J. Mason, R. R. Hill, L. Mönch, O. Rose, T. Jefferson, J. W. Fowler eds.," pp. 1922-1930, 2008.

[7] C. B. Joung, J. Carrell, P. Sarkar, and S. C. Feng, "Categorization of indicators for sustainable manufacturing," Ecol. Indic., vol. 24, pp. 148-157, 2013, doi: 10.1016/j.ecolind.2012.05.030.

[8] T. Stock and G. Seliger, "Opportunities of Sustainable Manufacturing in Industry 4.0," Procedia CIRP, vol. 40, no. Icc, pp. 536-541, 2016, doi: 10.1016/j.procir.2016.01.129.

[9] S. Editor, Front Matter. 2014.

[10] "13 Green Manufacturing.pdf." .

[11] A. M. Deif, "A system model for green manufacturing," J. Clean. Prod., vol. 19, no. 14, pp. 1553-1559, 2011, doi: 10.1016/j.jclepro.2011.05.022.

[12] W. Widada, "Reduce The Risk of Atherosclerosis through the wet Cupping Therapy," J. Med. Sci. Clin. Res., vol. 6, no. 11, pp. 581-586, 2018, doi: 10.18535/jmscr/v6i11.102.

[13] S. Sih, W. Wijayanti, and P. D. Sukmawati, "Potensi Limbah Serat Kayu Dari Pelepah Pisang Kering Sebagai Bahan Baku Pembuatan Frame Kacamata," pp. 340-342.

[14] S. Wardani, "Pemanfaatan Limbah Batu Bara ( Fly Ash ) Untuk Stabilitas Tanah Maupun Keperluan Teknik Sipil Lainnya Dalam Manggurangi Pencemaran Lingkungan," Pengukuhan Guru Besar Fak. Tek. Univ. Diponogoro, pp. 1-71, 2008. 